\title{
Pitting corrosion in pipeline steel weld zones
}

Igor A Chaves and Robert E Melchers

Centre for Infrastructure Performance and Reliability, The University of Newcastle, Australia

\begin{abstract}
:
Steel pipelines externally exposed to seawater pit more severely in heat-affected weld zones but longer-term quantitative data are scarce. Maximum pit depths and variability are reported for the longitudinal weld in API X56 Spec $5 \mathrm{~L}$ grade steel pipeline samples exposed continuously to natural Pacific Ocean seawater for 3.5 years. For the first year maximum pit depths and pit depth variability for the different weld zones were very similar. Both became much greater subsequently, with the greatest increases for the heat affected zone. This is compared with steel composition and grain size and potential reasons for the observations discussed.
\end{abstract}

Keywords: A: Steel, B: weight loss, modelling studies, C: Pitting corrosion, welding, pipelines.

Corresponding Author: Igor A Chaves igor.chaves@uon.edu.au +61 (02) 49217844

\section{Introduction}

Pitting corrosion is an important design consideration for containment such as required for steel pipelines used in the offshore oil and gas industry. There is extensive reliance on cathodic protection and protective coatings but corrosion still appears as one of the main causes of failure in the marine offshore environment, perhaps because current anti-corrosion measures are not always sufficient [1].

For weld zones, a generally accepted explanation of sensitization assumes that at sensitization temperature, chromium carbides precipitate at the grain boundaries, causing impoverishment of the adjacent matrix and therefore expected to be susceptible to both intergranular and pitting corrosion. Welded pipelines are widely used and for these the most severe pitting corrosion has been observed to occur primarily at and near the welds. Such pitting tends to occur at very different rates in the parent metal, the heat affected zone (HAZ) and in the weld metal [2, 3]. The HAZ is present on either side of a weld seam as a result of the thermal gradient set up between the weld metal and the parent metal [4]. This region of parent metal has been heated briefly to temperatures approaching the melting temperature of the steel and then cooled rapidly [2]. In contrast, general corrosion loss, important for strength considerations, tends to occur at a more moderate rate [1].

It is well-known that pitting corrosion theories can be divided roughly into two broad groups depending on the model of passivity considered. One assumes that pitting is a result of competitive adsorption between oxygen and halide anions and the other assumes the necessity of the existence of passive films, with some kind of local breakdown of the film occurs during pitting. It also is well-known that pitting generally initiates at surface in-homogeneities, either physical or chemical, including inter-metallic phases, non-metallic inclusions, grain boundaries, dislocations, defects or mechanically damaged sites $[5,6]$. For welds, the deepest pit depths have been associated with factors such as surface finish, thermal stresses and with variations in grain structure between the weld metal, HAZ and parent metal [7, 8, 9]. This has been observed both for mild and for stainless steels by Hunkler and many others $[3,10,11,12,13]$. The more severe pitting in the HAZ of welds has been attributed to material microstructure and to differences in material properties [4, 14]. 
For structural steels in seawater, pit initiation occurs very soon after first immersion $[15,16]$. Typically, the maximum pit depth increases significantly after some initial period of exposure that lasts from months to years, depending on water temperature [15]. This increase in maximum pit depth has been attributed, in part, to the development of anaerobic conditions at the surface. These can be favourable to corrosion through sulphate-reducing bacteria (SRB) $[17,18]$.

Corrosion of steel in a marine environment is known to depend on many factors including material composition, seawater chemistry, $\mathrm{pH}$, dissolved oxygen content, salinity, galvanic interactions, temperature and fluid velocity characteristics $[6,19]$ but increasing attention has been given also to the potential involvement of microbiological influences, including the effects of the presence of appropriate bacterial colonies and the availability of both energy sources (electron transfer) and nutrients sufficient to sustain bacterial metabolism [20]. It has been proposed that to obtain realistic, industry relevant, information about and quantitative results for the corrosion of steels in seawaters an appropriate natural seawater testing regime is preferable to laboratory-based studies even though a degree of experimental control may be lost [21]. This is extended herein to apply also to weld corrosion and in particular to pitting corrosion of welds. For that purpose realistic specimens with a normal material composition(s) and with a commercial external surface finish were employed, similar to earlier tests [13].

The present paper is concerned with the development with time of maximum pit depth and its variability for pitting corrosion along the external longitudinal weld of steel pipelines made to specification X56 of API Spec 5L exposed to natural seawater. The results of a 3.5 year study of samples of longitudinal welds exposed to Pacific Ocean seawater are described, mainly in terms of the evolution with time of the maximum pit depth and its variability for each of the three zones (weld zone, HAZ and parent metal).

In the next section the experimental program is described, followed by observations of the material composition and grain structure. This is followed by an analysis of the progression of maximum pit depth with increased exposure period for up to 3.5 years as well as an analysis of variability in maximum pit depth, based on multiple coupon exposures.

\section{Materials and methods}

The test program consisted of field exposures of coupons taken from commercial, industry-standard API Spec 5L X56 longitudinal seam welded pipe of $168.3 \mathrm{~mm}$ external diameter and $4.2 \mathrm{~mm}$ wall thickness. The coupons were $100 \mathrm{~mm}$ x $50 \mathrm{~mm}$ in size and cut from the pipe such that the longitudinal seam weld was along the $50 \mathrm{~mm}$ part of each coupon. A $10 \mathrm{~mm}$ diameter hole was drilled into one leg of each coupon to allow attachment to $300 \mathrm{~mm}$ diameter PVC exposure pods similar to those that have been used in previous immersion tests. The coupons were attached using nylon nuts and bolts. Prior to exposure the coupons were prepared and cleaned to ASTM standards $[22]$.

The exposure tests were conducted from the jetty at the Royal Australian Navy facility at Jervis Bay, NSW where previous exposure tests have been conducted also. Samples and pods were suspended from one of the main piers at half-tide level. This practice is considered to be consistent with ASTM Standard G52-00 specifications [22].

Triplicate coupons were recovered at regular intervals over a 3.5 year period. They were cleaned of major bio-fouling and then immediately taken to the laboratory and samples of rusts taken. They were then cleaned of easily removable loose rusts before being subjected to final electrolytic cleaning to ensure no significant removal of base metal [23]. The electrolytic method as specified in ASTM standard G1-03 [23] is known also as electrolysis. It has the virtue over weak acid cleaning 
in that it removes corrosion products without significant removal of the base metal. It uses the passage of an electric current $(0.25 \mathrm{Amp})$ through the samples immersed in a weak alkaline solution to convert some of the corrosion products into a more stable form and loosening the remaining corrosion products. This leaves a deposit that is easily removed by washing under tap water. Figure 1 shows a typical example of a coupon before and after cleaning, including the significant size of some of the pits. The results for pit depth measurements are described in the next section.

Figure 1. Typical pipeline steel coupons after exposure and before and after cleaning. Coupon was exposed for 148 weeks.

The chemical composition of the pipe steel is given in Table 1. Composition analyses conducted by two independent laboratories both found that the parent metal, the heat affected zone and the weld metal all had essentially the same composition. This is consistent with the pipe material being low carbon steel and also with the weld being a seam weld (electric resistance weld). Such welds are made with using an autogenous weld process in which high energy input is used to melt the very edges of the pipe metal to permit bonding without use of a filler metal [24]. This causes only very subtle changes in the metal composition but it will change the microstructure.

Table 1. Chemical composition of pipe material to API 5L (weight \%).

The metal microstructure was examined at typical cross-sections. Figures 2-4 show samples of the microstructure for each of the parent metal, HAZ and weld zone, respectively. The parent metal grain structure shows a range of grain sizes and inclusions mostly about 5 microns in equivalent diameter but some elongated slightly too around 7 microns. In comparison the HAZ shows a more uniform and more elongated grain structure with slightly larger grains. The inclusions are much more numerous than for the parent metal although of comparable size. The weld zone has a fine, mainly equiaxed, grain structure with similar sized grains. There are relatively few inclusions compared with the HAZ but about similar in number compared to the parent metal although somewhat more clustered. Visual inspection showed that in each case the grains were predominantly ferrite with small islands of pearlite - the latter small in size for the parent metal and progressively more elongated and flatter for the HAZ and the weld metal.

Figure 2. Microstructure of the Parent Metal zone.

Figure 3. Microstructure of the Heat Affected Zone.

Figure 4. Microstructure of the Weld Zone.

\section{Results for maximum pit depth}

Triplicate coupons were retrieved at each recovery stage. They were examined carefully for pitting and in particular for the location of the deepest pits. Both sides of each coupon were examined and pit depths measured in order to increase the overall number of pit depth samples. The area of each coupon, on both sides, was divided into the weld zone, the HAZ and the parent metal based on the extent of such zones visible by physical examination of several new, unexposed and polished samples. Figure 5 shows the size adopted for each zone. It also shows, for a typical case, the 3 sets of locations of the 5 deepest pits in each zone. Note that Figure 5 shows just one sample, out of a total of 21 ( 7 groups of triplicate coupons), that was examined to delineate the three zones. The deepest pits were in fact ascertained by measuring multiple pit depths and selecting the deepest. These have been marked on Figure 5. 
The depth of pits was measured in two different ways. For the coupons subject to exposure periods less than one year the depth was measured using a microscope focussed successively on the pit base and on the surrounding surface, thereby obtaining relative pit depth. For the pits at longer exposures it was more convenient to measure the pit depth relative to the surrounding metal using a dial gauge with a specially designed sharp probe to ensure the full depth of the pit could be measured. This technique gave a sensitivity of around $0.002 \mathrm{~mm}$.

Figure 5. Size adopted for each zone and a typical set of locations of the 5 deepest pits in each zone (PM parent metal, HAZ heat affected zone, WZ weld zone)

Relative pit depth may be converted to an estimated absolute pit depth through the device of assuming that the mass loss of the total coupon can be approximated as uniform over the surface and large enough that the error in neglecting the mass loss within the pits themselves can be ignored. The average corrosion loss is then added to the relative pit depth to obtain an estimate of the absolute pit depth. This approach has been used in many previous investigations $[5,16,17]$.

Figures 6-8 show, for each of the three zones, the estimated absolute pit depths for the 5 deepest pits for each of the triplicate coupons retrieved at each time point in the testing program as a function of time of exposure. In some cases it was not possible to measure 5 pits on a surface of a zone and for this reason there are, in some cases, fewer than 15 data plots recorded.

Added to the data points are the trends for the maximum pit depth as a function of exposure period and the average of the 5 deepest pits as a function of time. It is evident that at some exposure periods (around 72 weeks and after 125 weeks) there was very considerable scatter in the pit depths recorded. This is consistent with findings earlier for coupons of mild steel, and is the result of variability in (i) the change in the governing corrosion process and (ii) the possible influence of MIC in the corrosion process for longer exposures [25].

Figure 6. Pit depth data for observed deepest pits, mean and maximum trends for parent metal.

Figure 7. Pit depth data for observed deepest pits, mean and maximum trends for the HAZ.

Figure 8. Pit depth data for observed deepest pits, mean and maximum trends for the weld zone.

Following the conventional practice, the scatter in the data may be represented through an extreme value distribution. To determine whether an extreme distribution is an appropriate model for the uncertainty associated with pit depth, it is conventional first to rank the maximum observed pit depths and then to assign each a rank order occurrence frequency. The pit depth data is, conventionally, plotted along the horizontal axis of so-called Gumbel Probability paper. The associated rank order frequencies are then plotted along the vertical axis. It is distorted such that the probability is represented by the standardized variable $\mathrm{W}$. This has the result that if the data is Gumbel distributed the plot is linear. The standardized variable $\mathrm{W}$ is defined [26] as $\mathrm{W}=(\mathrm{y}-\mathrm{u}) \alpha$, further defined through $\mathrm{F}_{\mathrm{y}}(\mathrm{y})=\mathrm{F}_{\mathrm{w}}[(\mathrm{y}-\mathrm{u}) \alpha]$ with $\mathrm{F}_{\mathrm{w}}(\mathrm{w})=\exp \left(-\mathrm{e}^{-\mathrm{w}}\right)$ and $\mathrm{f}_{\mathrm{y}}(\mathrm{y})=\alpha \mathrm{f}_{\mathrm{w}}[(\mathrm{y}-\mathrm{u}) \alpha]$, where $u$ and $\alpha$, respectively, are the "mode" and "slope" of the Gumbel distribution and related to the mean $\mu_{\mathrm{y}}$ and standard deviation $\sigma_{\mathrm{y}}$ through $\mu_{\mathrm{y}}=\mathrm{u}+1.1396 / \alpha$ and $\sigma_{\mathrm{y}}=0.40825 \pi / \alpha$.

Gumbel plots for the data in each of the three zones are shown in Figures 9-11 for each zone respectfully. The best fit straight lines are shown for each data set in each zone. Note that each set of data (i.e. for each exposure period and for each zone) consisted of 5 deepest pit depth readings on each of triplicate coupons thus generating 15 maximum pit depth readings, per zone, per each period of time. The same horizontal scale is used in Figs 9-11 to facilitate direct comparison of the figures. 
Figure 9. Gumbel plot for maximum pit depth data for observed deepest pits for parent metal zone with fitted lines corresponding to a Gumbel Distribution.

Figure 10. Gumbel plot for maximum pit depth data for observed deepest pits for HAZ with fitted lines corresponding to a Gumbel Distribution.

Figure 11. Gumbel plot for maximum pit depth data for observed deepest pits for weld zone with fitted lines corresponding to a Gumbel Distribution.

\section{Discussion}

It is apparent from Figures 6-8 that the maximum pit depth in each of the zones increases very rapidly soon after first exposure and then is almost steady for the remaining early exposure period (0-55 weeks). The maximum pit depths are very similar for the three zones although about $25 \%$ higher for the HAZ. After 55 weeks the maximum pit depth increases rapidly in all three zones but more rapidly in the HAZ. At about 100 weeks of exposure the maximum pit depth in the HAZ is $50-100 \%$ deeper than in the other zones. After that the maximum pit depth in the weld zone and in the HAZ continues to increase faster than in the parent metal. Generally similar trends apply for the average pit depths.

Generally similar observations have been made previously in the corrosion literature about the relative magnitude of the pit depths in the three weld zones, both for pit depths in weldments and in welded pipelines such as presented by Eid [13]. The author and his colleges also state that the differences have been attributed to differences in micro-structure [14] but detailed reasons have not been proposed. There is also some empirical support that small differences in composition can influence the depth of pitting, at least for smaller individual coupons [27]. However, this may not extend to long corrosion zones such as welds along pipelines or to the extended HAZ along these welds. In addition, Table 1 shows that in the present study there is no significant difference in steel composition between the three zones. It follows that the observed difference in maximum pit depths between the zones cannot be the result of differences in composition.

The present results do show clear differences in microstructure (Figs 2-4). Most noticeably the HAZ has a greater number of inclusions or grain structure boundaries and mostly these are clustered in significant groups (Fig 3). Such localized microstructures are well-known as potential sites for pit initiation [28]. However, by itself this cannot explain the initially small difference in maximum pit depth (for 0-55 weeks) as against the subsequent much greater difference, after about 55 weeks, between the HAZ and the others.

One possible explanation for the observation of a small increase in maximum pit depth followed later by a much larger effect is that the localised defects between the grains shown in Fig 2-4 exercise an influence in pitting corrosion through the development of localized anoxic corrosion conditions. It is well known that corrosion under these conditions can be severe [28]. It is clear, however, that the effect will depend also on the time span over which localized anoxic conditions can prevail. On first exposure a number of processes will occur, including, pit initiation [28] and for natural seawater, colonization by biofilm and bacteria [29]. This is likely to involve localized anoxic conditions in the surface defects and in the biofilm [29]. However, as oxygen diffusion conditions take over the overall corrosion process and as rust layers develop the relative role of the anoxic niches will reduce [30] and this can be taken as reflected in the similar rate of increase of maximum pit depth for the three zones in the period (0-55 weeks). As the rust products build-up, however, oxygen diffusion declines and new local anoxic conditions can establish at the corroding surface. It is likely that the HAZ with its initially greater number of clustered micro-structural 
defects will have had these amplified during the period to 55 weeks. This will permit relatively more localized anoxic corrosion (including microbiological influenced corrosion) and is considered to be the cause of greater pit depths observed in the HAZ after about one year of exposure (see Figure 7). As noted by Eid, although the greater depth of pitting in the HAZ previously has been proposed to be the result of macro-structural differences $[13,14]$, detailed reasons for this have not been proposed previously.

The trend curves shown in Figures 6-8 are in all cases very similar to trends reported previously for the pitting corrosion of individual small mild steel coupons without welds [25]. That work proposed that there were successive changes in the corrosion process, commencing with very rapid pit initiation, followed by an oxygen diffusion rate controlled oxidation process (concentration control, diffusion control) and eventually, at a period of exposure dependent on water temperature, a relatively sudden increase in the rate of corrosion. Following this the corrosion rate then tends to decrease with further exposure. These later periods have been interpreted as involving corrosion processes that are partly or wholly anoxic, including hydrogen reduction and microbiologically influenced corrosion [25]. The present results are consistent with the earlier observations.

Figures 6-8 show very clearly that the widely adopted power law often used [5] to describe the development in time of maximum pit depth $d(t)=A t^{B}$, where $d(t)$ is pit depth and $A$ and $B$ are empirical constants, is not a good descriptor of the longer-term progression of maximum pit depth with time $t$, irrespective of whether maximum pit depth or average pit depth is considered. Evidently, this can have important practical implications or the prediction of future maximum pit depths in welded structures such as pipelines.

For mild steel coupons without welds, high variability in corrosion pit depth has been observed for extended exposure periods (after about 1.5 years exposure in the present water temperatures). This scatter was associated with the influence of microbiologically influences on corrosion under anoxic conditions [25]. A generally similar pattern of greater scatter in data is evident also in Figures 6-8. Further, the high degree of scatter for the longer exposure periods clearly is evident also in the Gumbel plots, Figures 9-11 since on such plots the slope of the data set is a measure of the degree of scatter. The reason for the high degree of scatter in the present data sets remains a matter for further investigation.

All three Gumbel plots, Figures 9-11, show that the data for exposure periods less than about one year are approximately linear. Following conventional extreme value interpretation, this indicates that the data can be taken as Gumbel distributed. However, for the longer exposure periods, after about 1.5 - 2 years, the data trends are distinctly non-linear. According to conventional extreme value analyses, this implies that the data are not Gumbel distributed [26]. Similar observations have been made earlier for the pitting of isolated small homogeneous coupons. For these there also was a distinct trend for smaller pit depths, identified as consistent with the Complementary Exponential distribution. For the deeper pits the Frechet distribution, which also is non -linear on the Gumbel plot was found to be appropriate [25]. The latter is more conservative than the standard Gumbel plot in that it predicts greater pit depths for a given probability of occurrence. Figure 12 shows that the data from the three weld zones for exposures at 3 years have trends that are consistent with the Complementary Exponential distribution for the shallower pits and the Frechet distribution for the deeper pits. This indicates consistency of extreme value probability distributions with the earlier results for homogeneous coupons.

Figure 12. Gumbel plot showing that the variability of maximum pit depth data sets for 3 years of exposure are generally consistent with the Complementary Exponential distribution for the shallower pits and with the Frechet extreme value distribution for the deeper pits. 
Some caution is required, however, in interpretations about applicable probability distributions when small corrosion coupons are used since the small size of the coupons and in particular the zones in which the pits were measured may bias the numerical values on the Gumbel plots. If the coupons are too small to capture a sufficient number of extreme pits, the data set that is actually recorded will be a sub-set of all pits that occur on a larger surface. In this sense the sampling carried out to estimate the Gumbel plots should be seen as an attempt at representative sampling under the assumption that this will generate a sufficiently sound estimate of the underlying pit depth distribution. Evidently, small areas may be sufficient while the pits are small and numerous. But this may not be the case for larger, deeper pits. The issue can be resolved only by sampling much larger weld zone areas along pipes.

Castillo stresses that in statistical analysis, including extreme value analysis, it is desirable for the data collected to be from homogeneous populations [31,32]. Typically in the literature dealing with extreme value corrosion pitting independence between pit depths has been assumed, without apparent justification [33, 34]. If the data set is sufficiently large and collected from extensive lengths and areas of pipeline weld, so-called 'asymptotic independence' often may be assumed [26], allowing application of the conventional extreme value theory. However, this would still not explain the marked change in the Gumbel trends seen in Figures 9-12 for the longer exposure periods. It is likely, in view of earlier observations [17], that these changes reveal a change in pitting mechanics, as has indeed been observed in field trials [35].

\section{Conclusions}

1. The maximum pit depth in the heat affected zone for longitudinal welds on pipeline steels is about $25 \%$ greater than for the adjacent parent metal and weld zones in the period 0-55 weeks of exposure, then rapidly increasing to being about $50-100 \%$ greater for exposures up to 3.5 years,

2. The corrosion trend with time shows that pit depth increases quickly immediately after first exposure, then steadies to a low rate of increase for about 55 weeks and then increases sharply but after about 100 weeks steadies to a much lower rate of increase. This applies to the parent metal, the HAZ and the weld metal but is most pronounced for the HAZ,

3. The above trend is similar to the trends observed earlier for mild steel exposed to marine environments but is very different from the power law conventionally adopted for the growth of maximum pit depth,

4. The variability in maximum pit depth changes with increased period of exposure, from relative small in the period 0-55 weeks to much larger immediately thereafter but then tending to a steady state after 3 years exposure. This was the case for each of the three zones although the HAZ and the weld zone showed considerably greater maximum pit depth variability than the parent metal. In each case the date were found to be consistent with the Gumbel extreme value distribution, although at longer exposures the Frechet distribution appears to be appropriate to describe the extreme value distribution for the extreme deepest pits.

5. There is no simple correlation between grain size and maximum pit depth. Instead it is proposed that the large increase in maximum pit depth after about 55 weeks exposure particularly for the $\mathrm{HAZ}$ is the result of the development of anoxic corrosion conditions in localized niches that have developed from earlier micro-structural defects that are significantly more numerous and clustered in the HAZ. This also explains the relatively small difference in maximum pit depth between the zones in the early period of exposure. 


\section{Acknowledgments}

The authors acknowledge the continued financial support provided by the Australian Research Council. AMOG Consulting provided the pipeline steel coupons used for the experimental work. Ms Amy Love, at one time an undergraduate student at Monash University contributed to the early experimental phase of this project whilst under the project supervision of the second author. Ms Karen Swain, Austpower Engineering, provided the metallurgical details given herein.

\section{References}

[1] Y. Bai, Q. Bai, Subsea Pipelines and Risers, Elsevier, Oxford, UK, 2005.

[2] A. Vetters, Corrosion in Welds, International Corrosion Conference, Melbourne, (1978) 13-17.

[3] F. Hunkler, G.S. Frankel, H. Bohni, On the mechanism of localized corrosion, Corrosion 43 (1987) 189-191.

[4] E. Mor, E. Traverso, G. Ventura, Intercrystalline corrosion of welded stainless steel pipelines in marine environment, Prakt. Metallogr. 11 (1974) 477-488.

[5] Z. Szklarska-Smialowska, Pitting Corrosion of Metals, National Association of Corrosion Engineers, Texas, USA, 1986.

[6] D.A. Shifler, Corrosion performance and testing of materials in marine environments, Proc. Electrochem. Soc. 14 (2004) 1-12.

[7] C. Kato, Y. Otoguro, S. Kado and Hisamatsu, Grooving corrosion in electric resistance welded steel pipe in sea water, Corros. Sci. 18 (1978) 61-74.

[8] H. Huang, W. Tsai and J. Lee, Electrochemical behaviour of the simulated heat-affected zone of A516 carbon steel in $\mathrm{H}_{2} \mathrm{~S}$ solution, Electrochim. Acta 41 (1996) 1191-1199.

[9] P. D. Bilmes, C. L. Llorente, C. M. Mendez and C. A. Gervasi, Microstructure, heat treatment and pitting corrosion of 13CrNiMo plate and weld metals, Corros. Sci. 51 (2009) 876-881.

[10] T. Szauer and J. Jakobs, The pitting corrosion of low alloy and mild steels, Corros. Sci. 16 (1976) 945-949.

[11] M. Sharifitabar, A. Halvaee and S. Khorshahian, Microstructure and mechanical properties of resistance upset butt welded 304 austenitic stainless steel joints, Mater. Des. 32 (2011) 3854-3864.

[12] B. T. Lu, Z. K. Chen, J. L. Luo, B. M. Patchett and Z. H. Xu, Pitting and stress corrosion cracking behaviour in welded austenitic stainless steel, Electrochim. Acta 50 (2005) 1391-1403.

[13] N.M.A. Eid, Localized corrosion at welds in structural and stainless steel under marine conditions Part 1, In: Proceedings of the International Offshore Mechanics and Artic Engineering Symposium, 3 (1990) 647-657.

[14] N.M.A. Eid, Localized corrosion at welds in structural under desalination plant conditions, Part 1: Effect of surface roughness and type of welding electrode, World Congress on Desalination and Water Reuse, Kuwait, 78 (1989) 397-406.

[15] G. T. Burstein, C. Liu, R. M. Souto and S. P. Vines, Origins of pitting corrosion, Corros. Eng. Sci. Techn. 39 (2004) 25-30.

[16] G. Butler, P. Stretton, J.G. Beynon, Initiation and growth of pits on high-purity iron and its alloys with chromium and copper in neutral chloride solutions, Br. Corros. J. 7 (1972) 168-173.

[17] R.E. Melchers, Pitting corrosion of mild steel in marine immersion environment - Part 2: Variability of maximum pit depth, Corrosion 60 (2005) 937-944.

[18] R.E. Melchers, Statistical characterization of pitting corrosion - Part 1: Review, Corrosion 61 (2005) 655-665.

[19] K. R. Tretheway and P. R. Roberge, Modelling Aqueous Corrosion from Individual Pits to System Management, Proceedings of the NATO Advanced Research Workshop on Modelling Aqueous Corrosion, Manadon, Plymouth, UK, 1993.

[20] B.J. Little, J.S. Lee, Microbiologically Influenced Corrosion, Hoboken, Wiley, 2007.

[21] J.S. Lee, R.I. Ray, B.J. Little, The influence of experimental conditions on the outcome of laboratory investigations using natural coastal seawaters, Corrosion 66 (2010) 1-6. 
[22] ASTM Standard: G52-00 Standard Practice for Exposing and Evaluation Metals and Alloys in Surface Seawater.

[23] ASTM Standard: G1-03 Standard Practice for Preparing, Cleaning and Evaluating Corrosion Test Specimens.

[24] O. W. Blodgett, Design of Welded Structures, James F. Lincoln Arc Welding Foundation, Cleveland, Ohio, USA, 1966.

[25] R.E. Melchers, Pitting corrosion of mild steel under marine anaerobic conditions - Part 1:

Experimental observations, Corrosion 62 (2006) 981-988.

[26] J. Galambos, The Asymptotic Theory of Extreme Order Statistics, second ed., Malabar, Krieger, New York, USA, 1987.

[27] R.E. Melchers, Effect of alloying on maximum depth of pits in mild steel in marine immersion environments, Corrosion 61 (2005) 355-363.

[28] G. T. Burstein, Electrochemistry of pit formation and growth, Proc. Electrochem. Soc. 19 (2004) 1-12.

[29] B. J. Little and J. S. Lee, Microbiologically Induced Corrosion, John Wiley \& Sons, Inc, New York, USA, 2007.

[30] R. E. Melchers, The transient early and the longer-term influence of bacteria on the marine corrosion of steel, Corros. Eng. Sci. Techn. 45 (2010) 257-261.

[31] E. Castillo and J. M. Sarabia, Engineering analysis of extreme value data: Selection of Models, J. Waterw. Port C. - ASCE 118(2) (1992) 129-146.

[32] P. J. Laycock and P. A. Scarf, Exceedances, extremes, extrapolation and order statistics for pits, pitting and other localized corrosion phenomena, Corros. Sci. 35 (1993) 135-145.

[33] M. Ahammed and R. E. Melchers, Probabilistic analysis of pipelines subjected to pitting corrosion leaks, Eng. Struct. 17 (1994) 74-80.

[34] G. Engelhardt and D. D. Macdonald, Deterministic prediction of pit depth distribution, Corrosion 54 (1998) 469-479.

[35] R. Jeffrey, R.E. Melchers, The changing topography of corroding mild steel surfaces in seawater, Corros. Sci. 49 (2007) 2270-2288. 


\section{Pitting corrosion in pipeline steels welds}

Table 1. Chemical composition of pipe material to API 5L (weight \%).

\begin{tabular}{llllllllllllll}
\hline & $\mathrm{C}$ & $\mathrm{Mn}$ & $\mathrm{P}$ & $\mathrm{S}$ & $\mathrm{Si}$ & $\mathrm{Ni}$ & $\mathrm{Cr}$ & $\mathrm{Mo}$ & $\mathrm{V}$ & $\mathrm{Al}$ & $\mathrm{Cu}$ & $\mathrm{Nb}$ & $\mathrm{Ti}$ \\
\hline Weld & 0.09 & 0.93 & 0.013 & 0.003 & 0.17 & 0.02 & 0.02 & $<0.01$ & 0.005 & 0.036 & 0.01 & 0.034 & 0.013 \\
\hline HAZ & 0.09 & 0.94 & 0.013 & 0.003 & 0.17 & 0.02 & 0.02 & $<0.01$ & 0.005 & 0.036 & 0.01 & 0.034 & 0.013 \\
\hline Parent & 0.09 & 0.93 & 0.013 & 0.003 & 0.16 & 0.02 & 0.02 & $<0.01$ & 0.004 & 0.036 & 0.01 & 0.034 & 0.013 \\
\hline API & $<0.25$ & $<0.95$ & $<0.05$ & $<0.06$ & & & & & & & & & \\
5L & & & & & & & & & & & & & \\
Spec. & & & & & & & & & & & & & \\
\hline
\end{tabular}




\section{Pitting corrosion in pipeline steels welds}

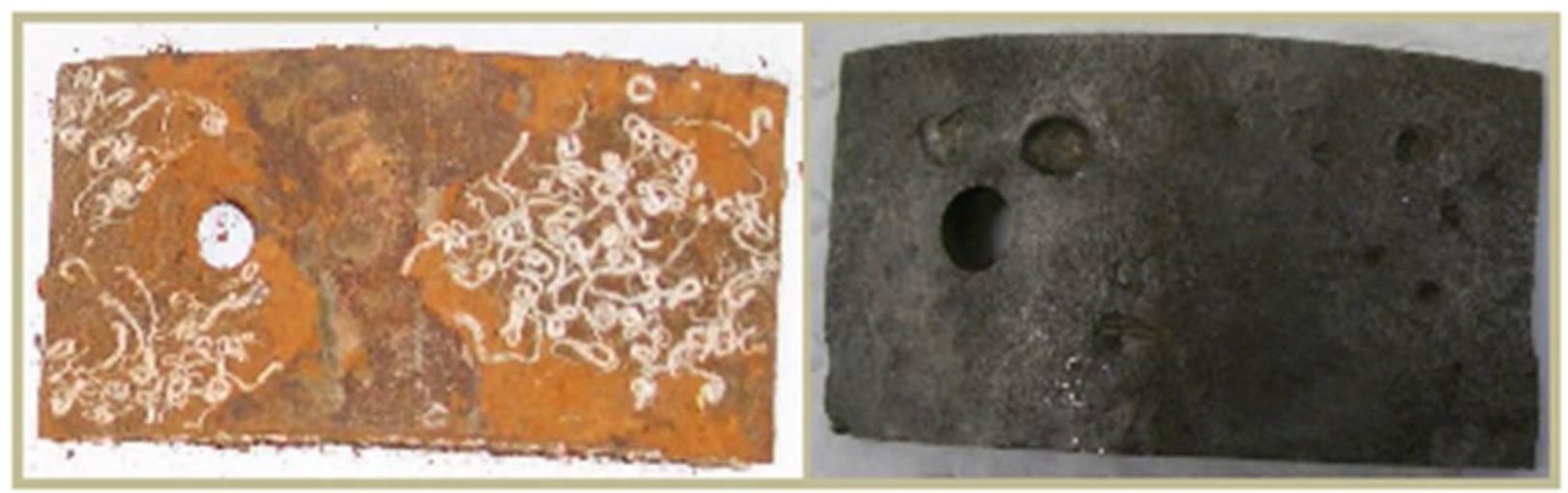

Figure 1. Typical pipeline steel coupons after exposure and before and after cleaning. Coupon was exposed for 148 weeks.
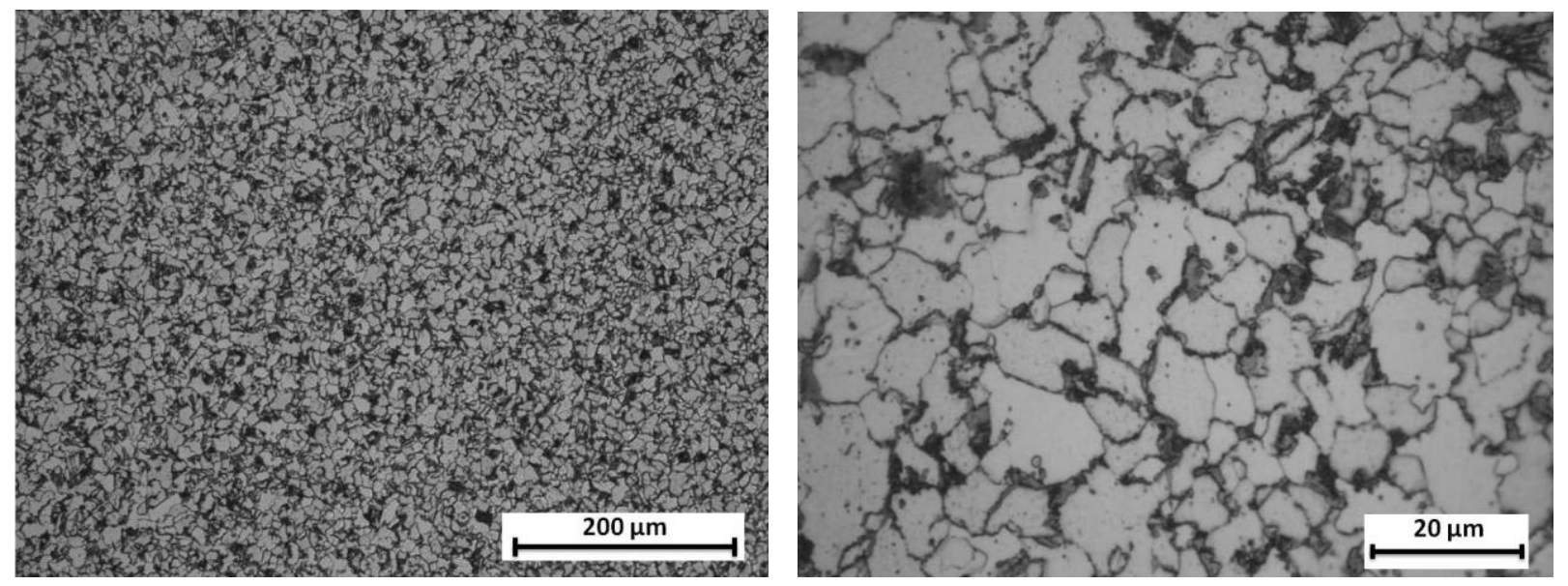

Figure 2. Microstructure of the Parent Metal Zone.
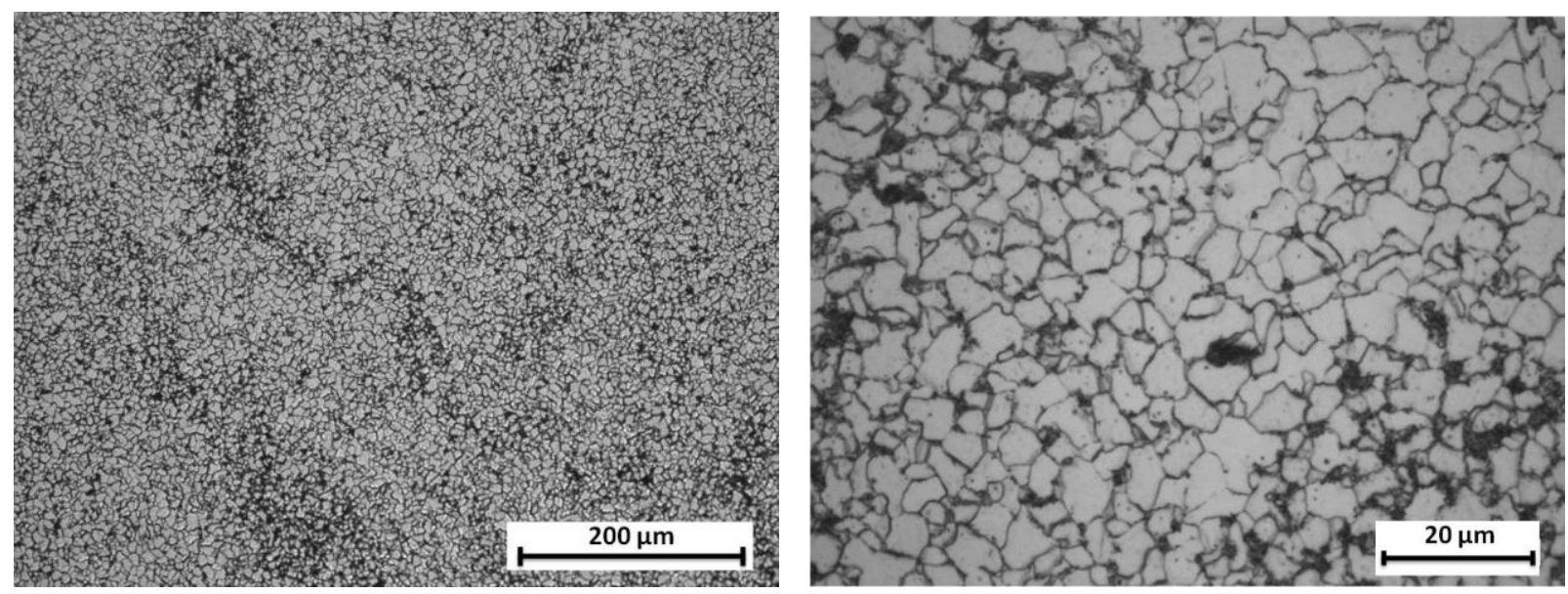

Figure 3. Microstructure of the Heat Affected Zone. 

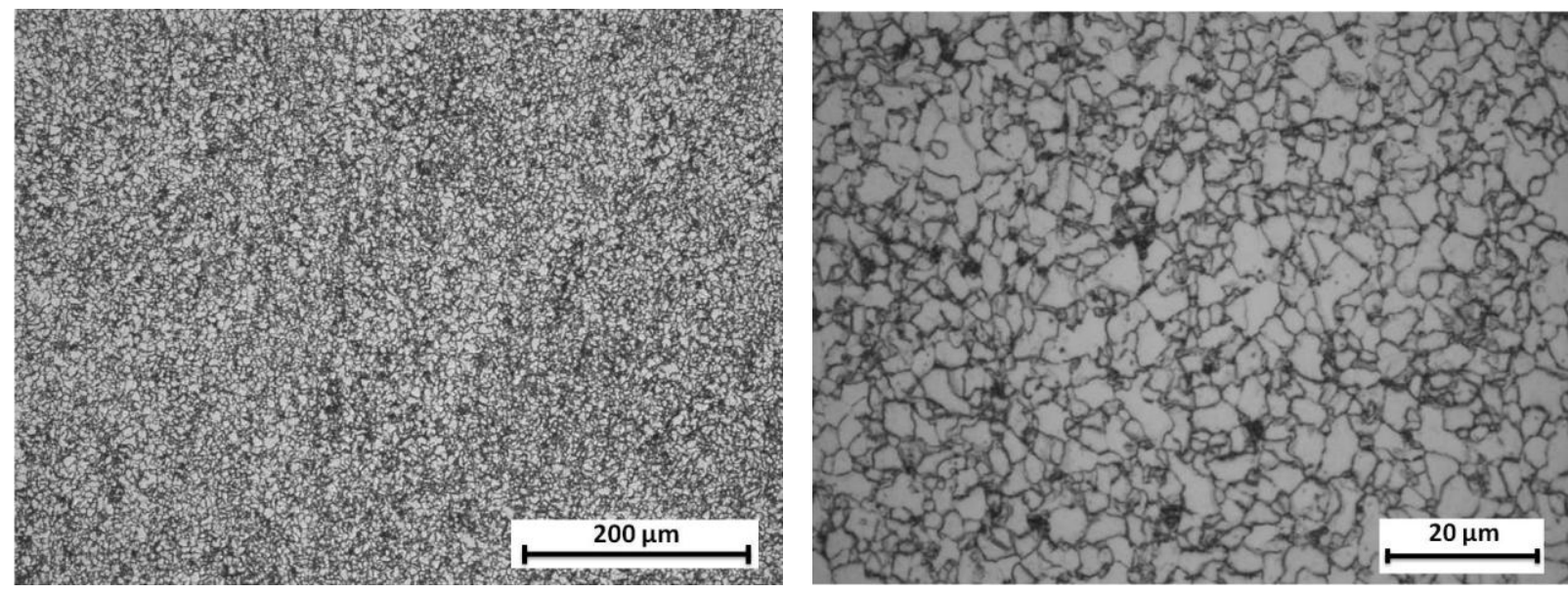

Figure 4. Microstructure of the Weld Zone.

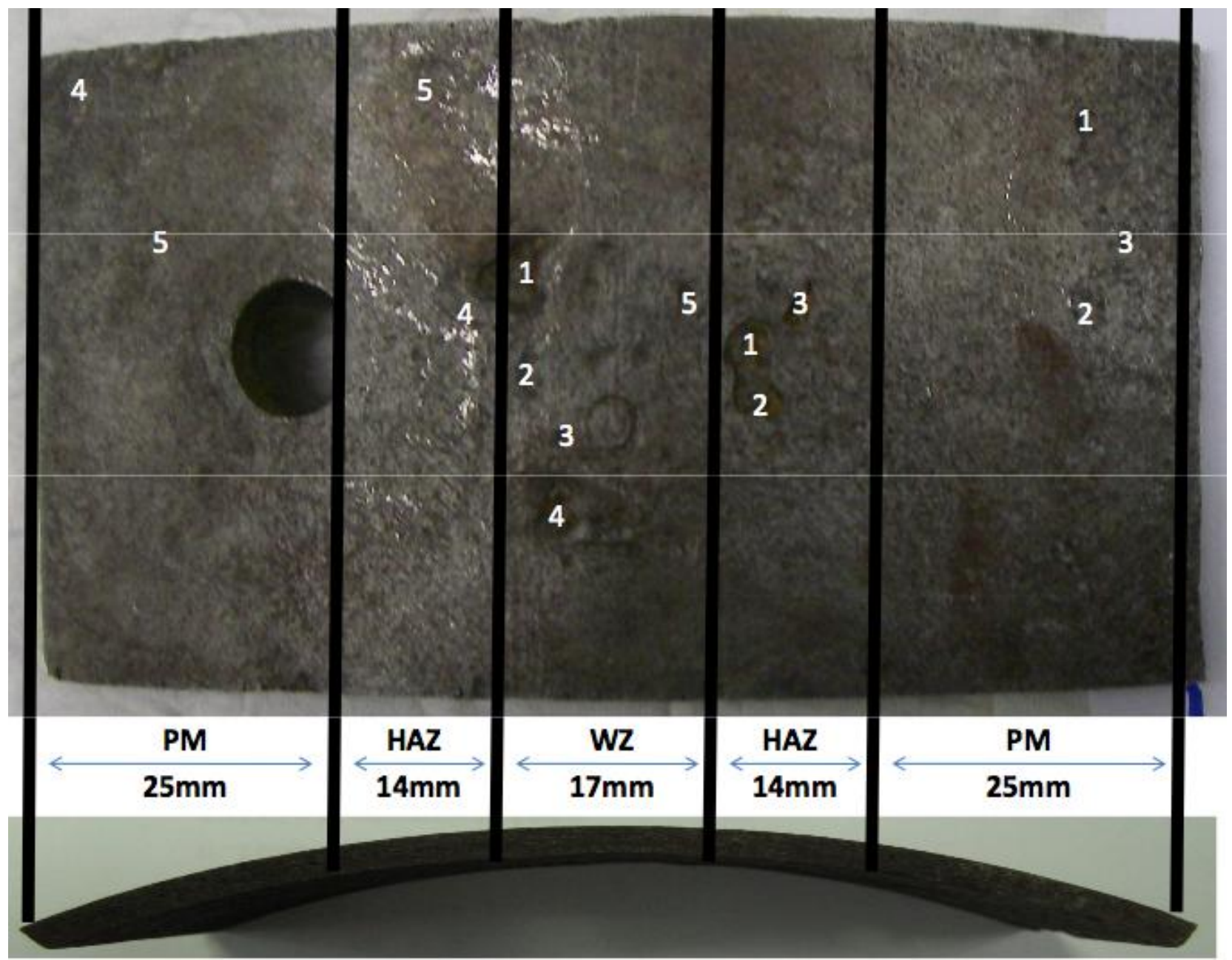

Figure 5. Size adopted for each zone and a typical set of locations of the 5 deepest pits in each zone (PM parent metal, HAZ heat affected zone, WZ weld zone). 


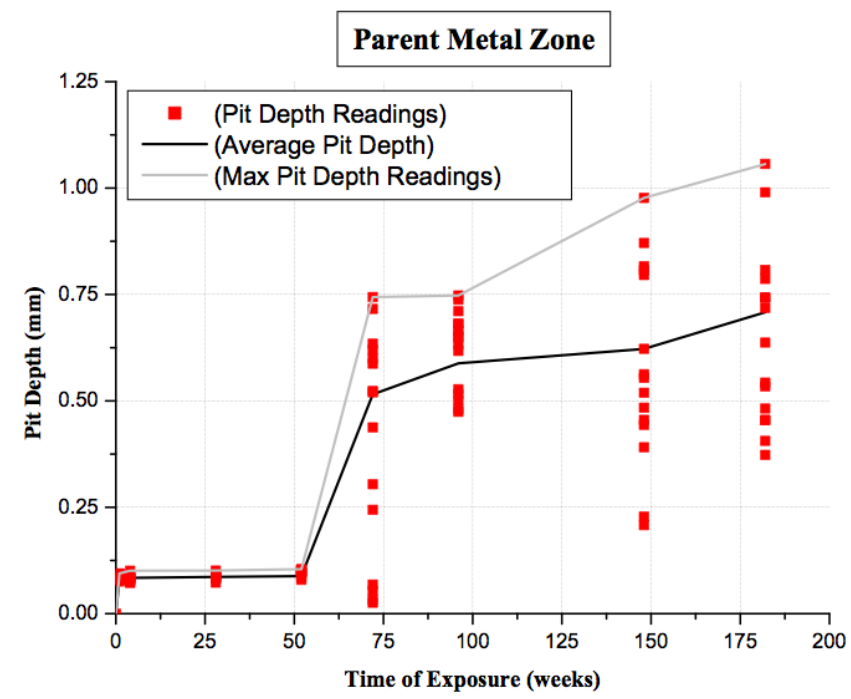

Figure 6. Pit depth data for observed deepest pits, mean and maximum trends for parent metal.

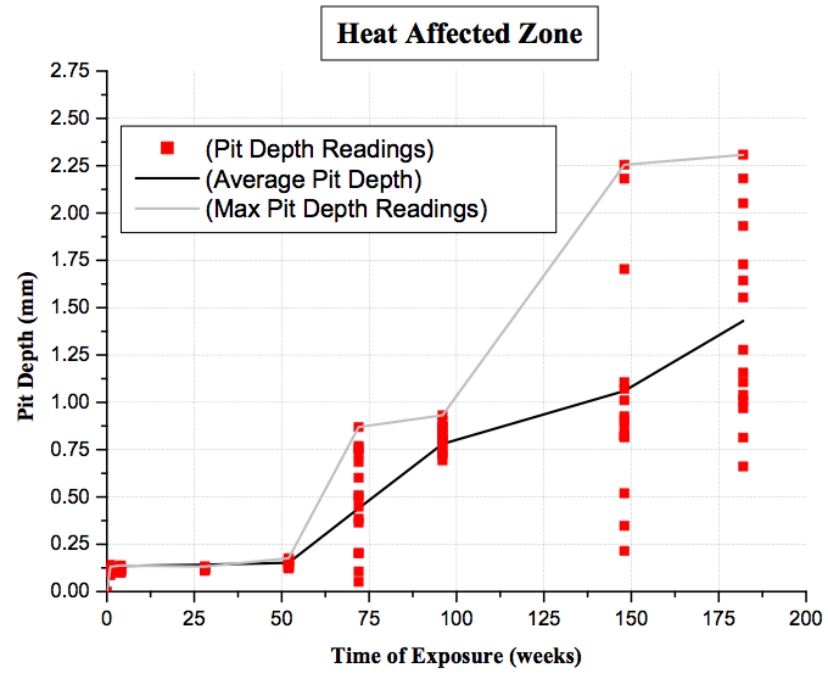

Figure 7. Pit depth data for observed deepest pits, mean and maximum trends for the HAZ.

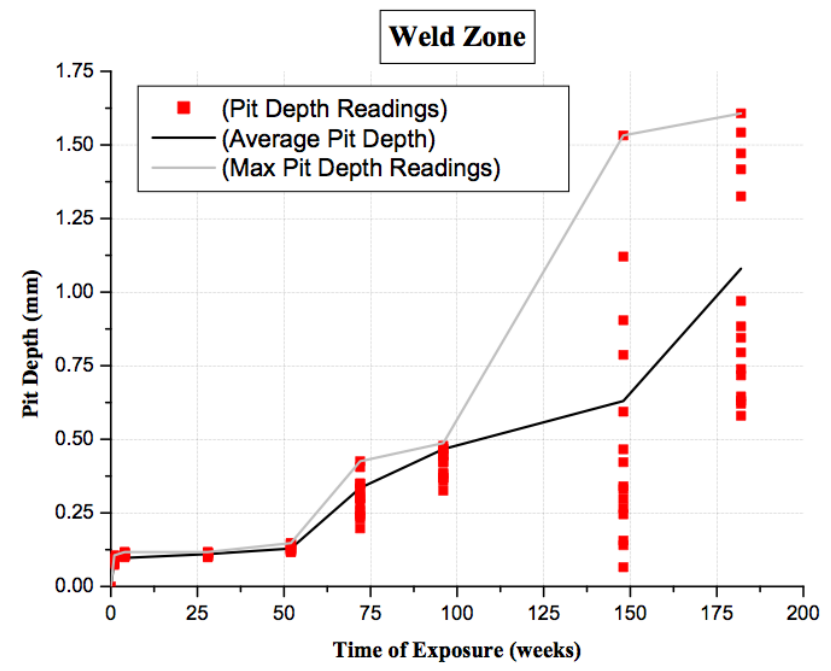

Figure 8. Pit depth data for observed deepest pits, mean and maximum trends for the weld zone. 


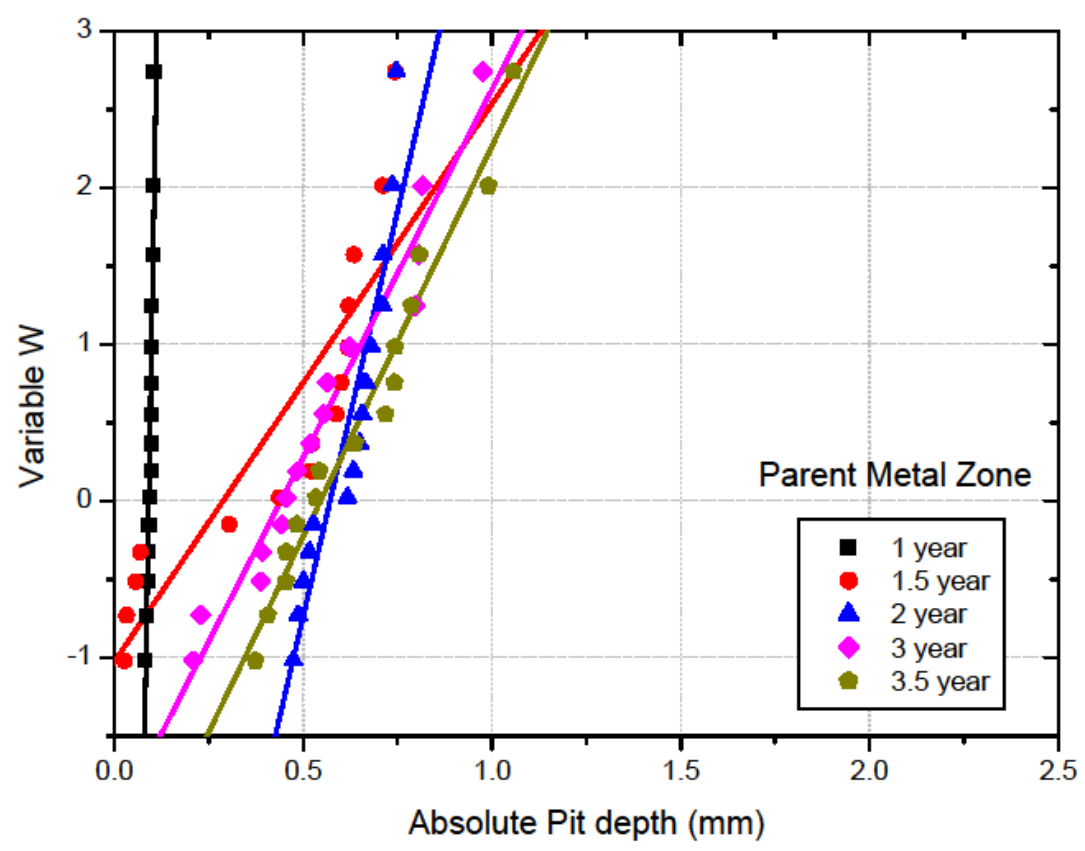

Figure 9. Gumbel plot for maximum pit depth data for observed deepest pits for parent metal zone with fitted lines corresponding to a Gumbel Distribution.

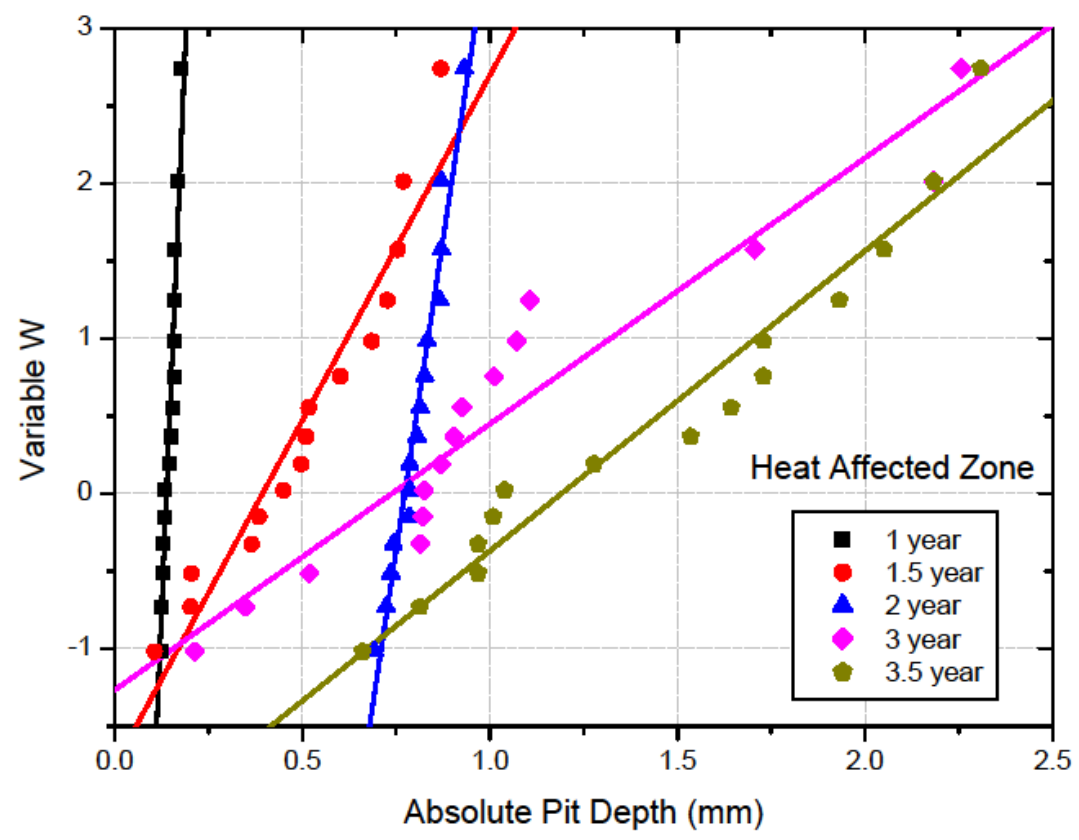

Figure 10. Gumbel plot for maximum pit depth data for observed deepest pits for HAZ with fitted lines corresponding to a Gumbel Distribution. 


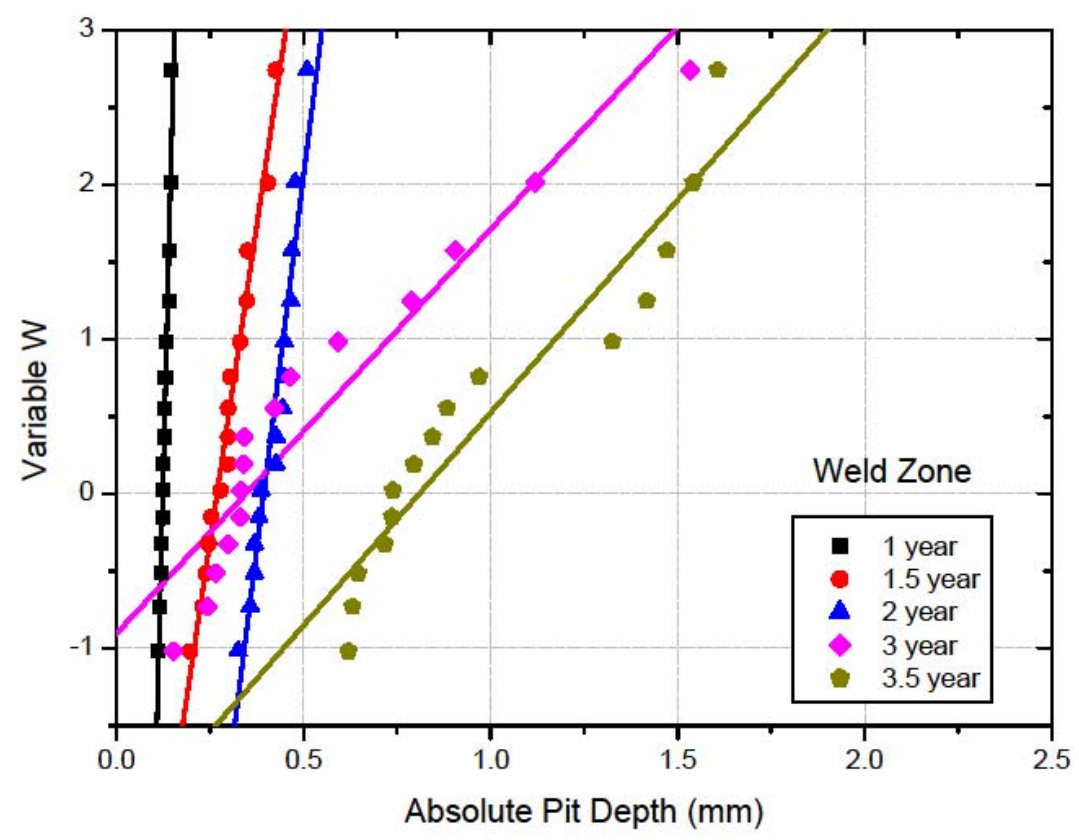

Figure 11. Gumbel plot for maximum pit depth data for observed deepest pits for weld zone with fitted lines corresponding to a Gumbel Distribution.

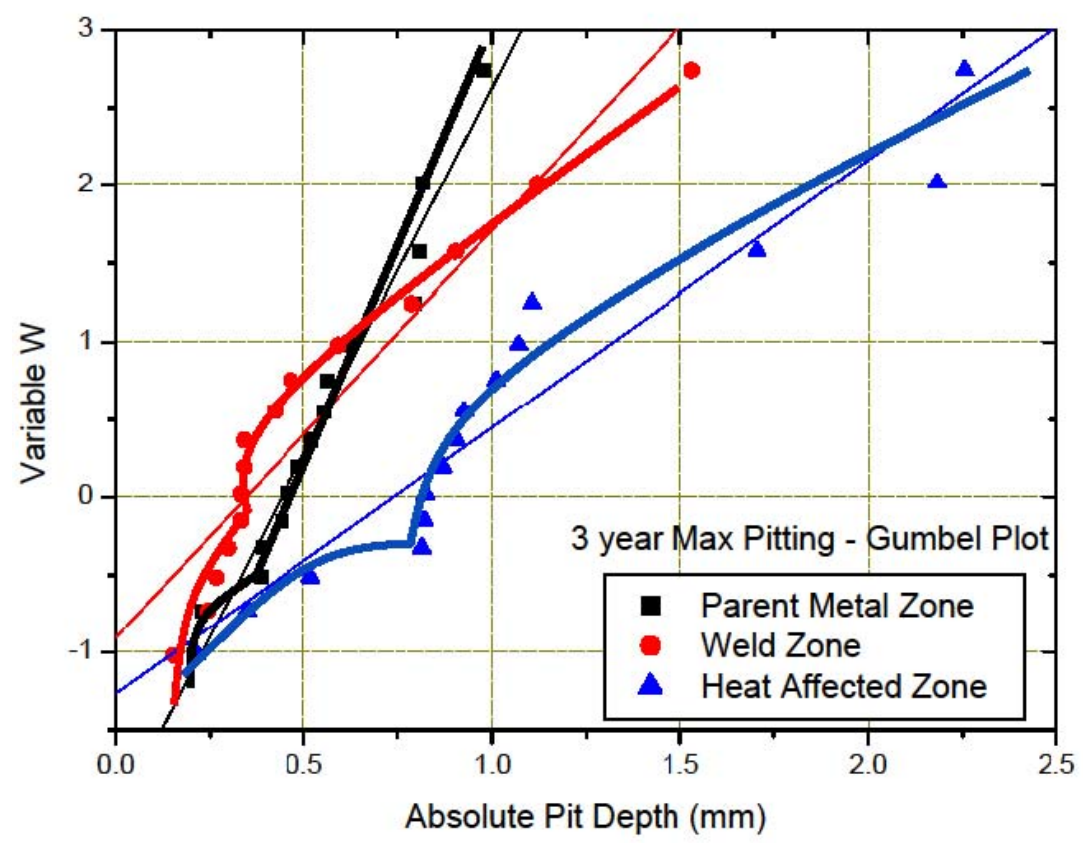

Figure 12. Gumbel plot showing that the variability of maximum pit depth data sets for 3 years of exposure are generally consistent with the Complementary Exponential distribution for the shallower pits and with the Frechet extreme value distribution for the deeper pits. 